\title{
ACONTECIMIENTO, EFECTUACIÓN Y SENTIDO EN LA FILOSOFÍA DE GILLES DELEUZE
}

\author{
Juan Pablo Esperón* \\ doi:10.11144/Javeriana.uph35-70.aesf
}

\section{RESUMEN}

Este artículo tiene dos objetivos: por un lado, aclarar qué designan las nociones de acontecimiento, efectuación y sentido en la filosofía de Deleuze; y, por otro, mostrar cómo estas nociones permiten pensar la singularidad sin que resulte explicada a partir de un fundamento trascendente y sus problemas derivados.

Palabras clave: Deleuze; acontecimiento; sentido; novedad; singularidad

* Universidad del Salvador, Universidad Nacional de La Matanza, Academia Nacional de Ciencias de Buenos Aires, CONICET, Buenos Aires, Argentina.

Correo electrónico:jpesperon@hotmail.com

Para citar este artículo: Esperón, J. P. (2018). Acontecimiento, efectuación y sentido en la filosofía de Gilles Deleuze. Universitas Philosophica, 35(70), pp. 207-228. ISSN 0120-5323, ISSN en línea 2346-2426 doi:10.11144/Javeriana.uph35-70.aesf. 


\title{
EVENT, EFFECTUATION AND SENSE IN DELEUZE'S PHILOSOPHY
}

\author{
Juan Pablo Esperón
}

\begin{abstract}
This article has two objectives: first, to clarify what the notions of event, effectuation and sense designate in Deleuze's philosophy. Second, to show how these notions allow us to think singularity without resorting to a transcendent foundation, thus circumventing derived problems.
\end{abstract}

Keywords: Deleuze; event; sense; novelty; singularity 


\section{Introducción. El problema del acontecimiento}

Luego de la Crítica eXtrema que Nietzsche hiciera, a fines del siglo XIX, de todos los resquicios de la filosofía y la cultura occidental, Deleuze, influenciado por estas ideas, postula un nuevo modo de hacer filosofía cuyo carácter distintivo es replantear los problemas ontológicos centrales de dicha actividad, a saber: qué es la realidad, por qué hay realidad pudiendo no haberla y qué es y cómo se da el sentido. De esta manera, postula un nuevo movimiento del pensamiento que tiene como eje fundamental la noción de acontecimiento y cuyo tratamiento se muestra en íntima relación con la noción de diferencia y contingencia.

¿Pero en qué consiste la novedad de esta noción? Esta novedad, como sugiere Scannone (2010, p. 8), hay que entenderla en relación con un doble giro crítico en la historia de la filosofía occidental. El primer giro es el copernicano, como crítica de la metafísica de los objetos absolutos. El segundo giro es el lingüístico, como crítica de la auto-absolutización del sujeto. Esta doble crítica de la nueva racionalidad permite repensar las categorías clásicas y modernas. Así, la identidad es sustituida por la alteridad o diferencia; la necesidad, por la gratuidad; la inteligibilidad, por la afectividad; la eternidad, por la novedad histórica, y la universalidad, por la unicidad del singular y por el universal situado.

Ante estas nuevas categorías, Scannone (2010) se pregunta abiertamente a qué responden en última instancia, es decir, qué es lo originario en ellas. La respuesta que esboza pareciera ser: estas categorías responden al acontecimiento. Se trata de una noción problemática, por cuanto se halla siempre en tensión: el acontecimiento es irrupción novedosa, pero es también el acontecer temporal en su devenir; emerge a partir de la diferencia, pero se muestra como la relación inmanente a la diferencia misma, que la hace real; es instancia última de sentido, pero también abismo desfondado.

La noción de acontecimiento, entonces, se muestra como suelo fértil para debatir al menos dos cuestiones capitales de la filosofía contemporánea. En primera instancia, el problema heredado del sistema hegeliano, el cual supone que la filosofía ha llegado a su culminación y se ha convertido en 'saber absoluto', incluyendo la totalización del saber que comprende al conjunto de la historia y su sentido. Deleuze rechaza decididamente esta alternativa impuesta por la coyuntura histórica y afirma la posibilidad de pensar la realidad de otro modo. Para 
ello postula la noción de acontecimiento en íntima relación con las nociones de diferencia, inmanencia y devenir.

Por otro lado, Deleuze postula estas nociones, también, para abordar de otro modo los problemas ontológicos reunidos bajo la noción de 'ser' que se han planteado en la historia de la filosofía, ya que sus desarrollos cargan con un caudal tan grande de problemas, significaciones e interpretaciones, que han terminado en muchos equívocos y malentendidos, hasta llegar al punto en que, actualmente, con la voz 'ser' quizás no pueda plantearse nada nuevo. En este sentido, a través de la noción de acontecimiento, Deleuze muestra la imposibilidad de un fundamento último de la realidad tal como se ha pretendido a lo largo de la historia de la filosofía occidental. Dicha imposibilidad concierne también a los intentos del estructuralismo y el cientificismo positivista, entre otras corrientes de pensamiento, cuya pretensión de universalismo y fundamentación absoluta fracasó en el siglo XX. Sin embargo, esto no significa negar los fundamentos o que debamos renunciar a la posibilidad de pensar nuestro mundo, pues el supuesto de esta nueva perspectiva filosófica es que, si aquel se define por su inalienable y radical contingencia, entonces la realidad siempre aparecerá fundada parcialmente. De este modo, la noción de acontecimiento relacionada con la diferencia y la contingencia posibilita fundar la realidad, pero justamente sobre la premisa de la imposibilidad de un fundamento último y absoluto.

Por todo ello resulta de suma relevancia para la coyuntura filosófica actual preguntarnos: ¿Por qué hablar de acontecimiento en filosofía? ¿Sabemos qué nombramos con la noción de acontecimiento? ¿La noción de acontecimiento remite al lado entitativo o al lado ontológico de la realidad de acuerdo con la ya conocida diferenciación heideggeriana? ¿Es la diferencia el lugar originario del acontecimiento? Por otro lado, ¿cómo se efectúa el acontecimiento?, ¿es posible explicar esta efectuación?

2. El acontecimiento, el sentido y la génesis de su efectuación

Deleuze Delimita una FORMA DE FUndamentación tradicional que se fue gestando y afianzando a lo largo de la historia occidental y que impide pensar fuera de ciertos límites preestablecidos. A esta forma de pensamiento Deleuze la denomina 'imagen dogmática' del pensamiento, con lo que designa una 
comprensión en la que el pensamiento remite a un fundamento trascendente como garante necesario y a priori de la rectitud del pensar. A partir de ocho postulados, Deleuze caracteriza y delimita esta imagen dogmática. El primer postulado, denominado del principio o de la cogitatio natura universalis, muestra el presupuesto, introducido en la filosofía por Descartes al inicio de la modernidad, según el cual el buen sentido o razón es la cosa mejor repartida entre los hombres como base para la reflexión. Se presupone la buena voluntad del ejercicio del pensamiento y del pensador como base para la recta reflexión filosófica. El segundo postulado hace referencia al sentido común, presupuesto por el cual se hace de este la facultad de concordia entre todas las facultades humanas y los entes a los que se aplica. El tercer postulado se refiere al reconocimiento, según el cual conocer es siempre reconocer. El cuarto postulado es el de la representación, a partir del cual se determina el representar claro y distinto como elemento superior del conocimiento que reduce toda diferencia a la identidad del concepto. El quinto postulado es el del error o negación, por el cual se determinan al error y a la negación como los principales riesgos para el pensamiento. El sexto postulado es el de la función lógica o de la proposición, postulado por el cual se designa el lugar del pensamiento a la proposición y sus funciones lógicas. Aquí se decide la verdad o falsedad del mundo en detrimento del sentido. El séptimo postulado es el de la modalidad, que privilegia la primacía de las soluciones sobre la producción de problemas. Finalmente, el octavo postulado, del fin o del resultado, es aquel por el cual se presupone que el conocimiento tiene por finalidad el saber y no el aprender (Deleuze, 2002, cap. 3).

Así pues, la filosofía deleuzeana tiene, entre sus tareas, impugnar estos postulados, ya que impiden pensar creativamente para producir una nueva imagen del pensamiento liberada de los límites designados por ellos. Como es sabido, la filosofía para Deleuze debe combatir toda mistificación de las formas de pensar imperantes para crear nuevos conceptos, nuevos sentidos y nuevas formas de vida. Esto lleva al pensador francés a abordar el problema del acontecimiento.

El acontecimiento emerge como un estallido diferencial de fuerzas, manifestándose en un estado de cosas (Žižek, 2014, pp. 23-24). Es una singularidad, es decir, en todo acontecimiento está presente el momento de su efectuación. Tal manifestación subvierte el estado de cosas imperante haciendo necesario redefinir a partir de ella tanto el statu quo actual, como el pasado y el futuro, pues pasado 
y futuro se resignifican a partir de la encarnación material del acontecimiento efectuado. En términos deleuzeanos, un acontecimiento es un movimiento nohistórico, una línea de fuga por el medio, una línea que desterritorializa para reterritorializar nuevamente:

Una de las objeciones que Hobbes le hace a Descartes ( 3 objeciones): que de "yo paseo", se podría concluir que "luego, yo soy un paseo". ¡Por supuesto!, hubiera contestado Deleuze. Incluso hay que ir más lejos: no soy Yo quien soy, sino que ante todo hay el acontecimiento, el paseo (Schérer, 2012, p. 38).

La noción de medio hace referencia en la filosofía de Deleuze a aquello que no tiene principio ni fin. El medio no es centro en el espacio, ni pasado, presente o futuro en el tiempo. Aquí no se está hablando ni de evolución ni de historia. Una línea que pasa por medio de las oposiciones metafísicas supone un acontecimiento (linea de fuga). Por ello la fundamentación metafísica resulta inapropiada para comprender el carácter inmanente y diferencial del acontecimiento. Para Deleuze y Guattari (2003), la filosofía de la diferencia y su íntima vinculación con la noción de medio pueden ser caracterizadas como rizomáticas:

Un rizoma no empieza ni acaba, siempre está en el medio, entre las cosas, inter-ser, intermezzo. El árbol es filiación, pero el rizoma tiene como tejido la conjunción ' y... y... y.... En esta conjunción hay fuerza suficiente para sacudir y desenraizar el verbo ser. ¿Adónde vais? ¿De dónde partís? ¿Adónde queréis llegar? Todas estas preguntas son inútiles. Hacer tabla rasa, partir o repartir de cero, buscar un principio o un fundamento, implican una falsa concepción del viaje y del movimiento (metódico, pedagógico, iniciático, simbólico...). [...] Entre las cosas no designa una relación localizable que va de la una a la otra y recíprocamente, sino una dirección perpendicular, un movimiento transversal que arrastra a la una y a la otra, arroyo sin principio ni fin que socava las dos orillas y adquiere velocidad en el medio (p. 56-57).

Los sentidos-acontecimientos, simbolizados por los rizomas, crecen y proliferan por todos lados, sin justificaciones últimas que permitan prever dónde crecerá el próximo rizoma, ya que siempre proliferan en medio o entre la maleza; ni en el centro justificador ni en la periferia justificada de la lógica metafísica, sino por el medio de o entre las oposiciones metafísicas. El medio o entre supone una constante tensión entre lo mismo y lo otro, entre el azar y la necesidad. Esto impide el 
aseguramiento total de lo real dentro de categorías objetivadoras de la metafísica. Por otro lado, la noción de medio permite la creación de sentidos, admitiendo que no hay arkhé fundamental y última cuyo carácter de verdad sea incuestionable. El acontecimiento, pues, desestabiliza y destruye la fijeza de las estructuras conocidas como mundo, yo y dios, ya que, como afirma Deleuze (1989), el acontecimiento "destruye al sentido común como asignación de identidades fijas" (p. 27).

Pero Deleuze (1989) aclara que no "debemos confundir el acontecimiento con su efectuación espacio-temporal en un estado de cosas" (p. 34). Cuando un acontecimiento se efectúa en un determinado estado de cosas (cuerpos), se lo percibe como una sucesión espacio-temporal donde el lenguaje penetra y recoge el momento de la inflexión diferencial de su aparición, i. e., el puro instante de su efectuación; y esa síntesis diferencial es la que produce el sentido. Por ello, Deleuze sostiene que el acontecimiento es el sentido, es el dador de sentido o, mejor aún, es el acontecimiento mismo el que se dona como sentido. Pero no debe pensarse que el acontecimiento tenga una naturaleza lingüística dada por su relación con el sentido. Estamos aquí en presencia del estatuto paradójico del acontecimiento, que se presenta tanto del lado entitativo de la realidad (del estado de cosas), como del lado de la lengua, aunque resulte inidentificable con ellos, pues en el acontecimiento hay algo que se sustrae a estos elementos como lo radicalmente diferente en cuanto que excede lo efectuado (lado ontológico): "Un acontecimiento es por consiguiente el efecto que parece exceder sus causas -y el espacio de un acontecimiento es el que se abre por el hueco que separa un efecto de sus causas-. [...] [Un acontecimiento es] un suceso que no está justificado por motivos suficientes" (Žižek, 2014, p. 17).

En suma, el acontecimiento está del lado de la efectuación de un determinado estado de cosas, a la vez que se diferencia de él, pero asimismo el acontecimiento aparece del lado del lenguaje, del que también se sustrae, pues es diferente a este. Más aún, el acontecimiento habita en el medio de esta doble diferenciación como aquello que es, a la vez, mundo y sentido, pero no identificándose con ellos, es decir, el acontecimiento se presenta como la doble afirmación del mundo y del sentido y es, a su vez, su radical diferenciación. Sin embargo, siempre queda algo del acontecimiento considerado en el plano entitativo que se sustrae y que resulta inaprensible por el lenguaje; siempre hay un resto inefectuable en toda efectuación porque el acontecimiento la excede. En últimas, el acontecimiento es 
[...] aquello que escapa a esta estructura, es decir, es el punto de inscripción de la contingencia histórica en una estructura formal. [...] El principio en sí mismo, en su pureza, ya está coloreado por la singularidad (...); es decir, la particularidad sostiene la pureza misma del principio. El elemento excesivo es por tanto un suplemento al Dos, a la pareja armoniosa, yin y yang, las dos clases [sociales], etc.; por ejemplo, el capitalista, el trabajador $y$ el judío; o, quizá, la clase alta, la clase baja, más la plebe. [...] Y es fácil ver en qué sentido esta Caída es acontecimental: en ella, la estructura eterna del lenguaje divino se integra en el flujo acontecimental de la historia humana (Žižek, 2014, p. 42-45).

Así, todo acontecimiento es inherente al sentido que se actualiza y adquiere forma en el lenguaje, conformando el mundo y su movimiento espacio-temporal, ya que es aquello que se materializa en el mundo y se deja envolver por el lenguaje.

Ahora bien, debemos preguntarnos cómo se produce la efectuación del acontecimiento. Deleuze explica esta efectuación a partir de la recepción de las filosofías de Spinoza y Nietzsche. Su elaboración comienza a partir de problematizar qué es y qué puede un cuerpo, abriendo la posibilidad de entenderlo en tanto relaciones entre términos (potencias-fuerzas) desiguales (diferencias intensivas) y no como totalidad (substancia).

\section{1 ¿QUÉ ES UN CUERPO?}

Para Deleuze, Nietzsche es el filósofo que pone nuevamente en primer plano la cuestión del cuerpo, reintroduciendo el problema de su potencialidad. Esto hace del cuerpo algo "sorprendente" y maravilloso, mucho más sorprendente que la conciencia (Deleuze, 1986, p. 60). Deleuze muestra, también, que este asombro por la potencialidad del cuerpo es el mismo asombro que el de la reflexión filosófica de Spinoza cuando afirma: "no sabemos lo que un cuerpo puede” (Eth. esc. 98b, prop. 2, III parte) ${ }^{1}$. Entonces se pregunta Deleuze (1986): ¿qué es el cuerpo? Y responde:

1 Recordemos que para Spinoza el cuerpo y el pensamiento son modos o maneras de actividad de una misma y única substancia infinita, "la potencia de pensar es paralela a la potencia de actuar de manera que la actividad y los cambios de las fuerzas físicas son siempre al mismo tiempo una actividad y una modificación de las fuerzas mentales" (Jaquet, 2007, p. 49). Pero debemos tener en 
Solemos definirlo diciendo que es un campo de fuerzas, un medio nutritivo disputado por una pluralidad de fuerzas. Porque, de hecho, no hay "medio", no hay campo de fuerzas o de batalla. No hay cantidad de realidad, cualquier realidad ya es cantidad de fuerza. Únicamente cantidades de fuerza, "en relación de tensión" unas con otras². Cualquier fuerza se halla en relación con otras, para obedecer o para mandar. Lo que define a un cuerpo es esta relación entre fuerzas dominantes y fuerzas dominadas. Cualquier relación de fuerzas constituye un cuerpo: químico, biológico, social, político. Dos fuerzas cualesquiera, desiguales, constituyen un cuerpo a partir del momento en que entran en relación: por eso el cuerpo es siempre fruto del azar, en el sentido nietzscheano, y aparece siempre como la cosa más 'sorprendente', mucho más sorprendente realmente que la conciencia y el espíritu. Pero el azar, relación de la fuerza con la fuerza, es también la esencia de la fuerza; no nos preguntaremos, pues, cómo nace un cuerpo vivo, ya que todo cuerpo es viviente como producto 'arbitrario' de las fuerzas que lo componen. El cuerpo es un fenómeno múltiple, al estar compuesto por una pluralidad ${ }^{3}$ de fuerzas irreductibles; su unidad es la de un fenómeno múltiple, "unidad de dominación" (pp. 60-61).

Un cuerpo no se define por lo que es, sino por lo que puede, y esto supone un quantum de fuerzas en relación. No podemos definir de antemano lo que un cuerpo puede, aquello de lo que un cuerpo es capaz, dado que depende de las relaciones de fuerzas que lo constituyen, de la capacidad de afectar y ser afectado, de multiplicar y crear conexiones y relaciones nuevas, de aumentar o no su capacidad de actuar. Un cuerpo deviene junto a otros cuerpos produciendo, afirmando relaciones, encuentros y conexiones; afirmando diferencialmente su poder. Un cuerpo es un proceso abierto y en formación continua, oscilante, que des-estructura toda forma a priori de fundamentación. Por todo ello afirma Deleuze (1986)

cuenta, también, que Deleuze, no desconociendo esto, pone, vía la filosofía de Nietzsche, el acento en el cuerpo por sobre el pensamiento.

2 Véase La voluntad de poder, II, 352 (Nietzsche, 2000, citado por Deleuze, 1986, p. 64).

3 Se introduce aquí el concepto deleuziano de multiplicidad. Contra Platón, lo real no remite a lo uno, ni siquiera a la dualidad, sino a una multiplicidad. No se parte de la identidad, sino de la diferencia. 
que "no sabemos de lo que un cuerpo es capaz" (p. 62). Un cuerpo es un flujo constante de fuerzas diferentes en relación con otros cuerpos, pero, a la vez, siempre es una totalidad inacabada e incompleta. Por ello no es posible delimitar, definir o identificar de antemano qué es y qué puede el cuerpo (Etchegaray et al., 2011, p. 234). Además, el cuerpo se sustrae a los límites del pensamiento representativo, dado que un cuerpo es siempre posibilidad de realizar diferencias siempre nuevas, pero un cuerpo siempre es más de lo que realiza, es un campo de fuerzas generativas y productivas actualizándose sin agotar su poder de cambio.

Un cuerpo no es lo que ocupa un lugar en el espacio. No se trata de un lugar o de un escenario previamente constituido donde la relación de fuerzas tendría lugar. Son las relaciones de fuerzas las que crean el medio o el escenario, pero tal escenario es siempre un resultado parcial, contingente y provisorio de las relaciones entre las fuerzas. Retomemos la definición de cuerpo: allí donde hay al menos dos fuerzas en relación. ¿De qué ámbito? ¿De qué tipo? De cualquier tipo, de cualquier ámbito: químico, físico, social, político, etc. Para Deleuze (1986) un cuerpo es un centro de potencia ${ }^{4}$, una relación de fuerzas producto de la voluntad de poder.

La voluntad de poder es el elemento diferencial de las fuerzas, es decir, el elemento de producción de la diferencia de cantidad entre dos o varias fuerzas supuestas en relación. La voluntad de poder es el elemento genético de la fuerza, es decir el elemento de producción de la cualidad que pertenece a cada fuerza en esta relación. La voluntad de poder como principio no suprime el azar, al contrario, lo implica (p. 77).

No debemos comprender aquí que la voluntad de poder quiera la potencia, ni que la desee como un fin, sino que es la potencia lo que quiere la voluntad. Lo anterior se debe a que la potencia es en la voluntad el elemento genético y diferencial, es decir, el elemento creador y dador de sentido, es el direccionador de las fuerzas. Una clara consecuencia de esta posición es que se desplaza a la voluntad

4 La noción de potencia no debe ser entendida en sentido aristotélico (como el movimiento de la sustancia del ser en potencia al ser en acto), sino que aquí debemos comprenderla como identificada, a su vez, con el acto, es decir, la potencia es siempre movimiento, flujo actual. En este sentido, la potencia es un movimiento de fuerza/poder que está totalmente efectuada en cada instante. Al respecto, véase el apartado 2.2 de este artículo. 
del rol central que Descartes le otorgaba en su gnoseología como dependiente de la conciencia y autoafirmando, a la vez, la propia identidad subjetiva. Aquí, en cambio, la voluntad remite a la potencia de actuar que Deleuze retoma de la filosofía de Spinoza a través de la noción de conatus, según la cual cada cuerpo tiende a preservarse en su ser, es decir, cada ente tiende a desarrollar todo lo que puede. Entonces la voluntad de potencia es el esfuerzo por llevar las fuerzas al límite de sus posibilidades (Dosse, 2009, p. 191). Así pues, Jaquet (2007) sostiene que "[...] transformando la voluntad de potencia (nietzscheana) en la potencia en la voluntad, Deleuze la acerca al conatus spinoziano y a su potencia, al mismo tiempo es determinante y determinada en función de sus relaciones con el mundo exterior" (p. 51).

Debemos señalar también que el azar siempre pone en relación por lo menos a dos fuerzas diferentes. La voluntad de potencia es el elemento diferencial y genético de la fuerza, es decir, ella determina la relación de una fuerza con otra al tiempo que produce la cantidad y la cualidad de las mismas. Además, al tiempo se manifiesta como un poder de afectar y ser afectado, ya sea por fuerzas superiores, ya sea por fuerzas inferiores.

La voluntad de poder es el elemento del que se desprenden a un tiempo la diferencia de cantidad de las fuerzas en relación, y la cualidad que, en esta relación, corresponde a cada fuerza. Aquí revela su naturaleza la voluntad de poder: es el principio de la síntesis de las fuerzas (Deleuze, 1986, p. 74).

Por ello la voluntad nunca se puede separar de la fuerza, de sus cualidades y de sus cantidades. La voluntad es al mismo tiempo determinada y determinante, cualificada y cualificante (Deleuze, 1986, p. 90). Tengamos en cuenta que la voluntad de poder no es la fuerza sino su posibilidad. Lo anterior quiere decir que hay que diferenciar la voluntad de la fuerza, puesto que la voluntad de poder es, como afirmamos arriba, la potencialidad de su afectividad. Esto podemos aclararlo al preguntar: ¿quién quiere? No se puede responder la fuerza, porque no es la fuerza quien quiere, sino que quien quiere es la voluntad, y ello no pude ser alienado ni delegado. Sin el elemento interno de la voluntad toda fuerza sería indeterminada. "La voluntad de poder, pues, se suma a la fuerza, pero como elemento diferencial y genético, como elemento interno de su producción” (Deleuze, 1986, p. 75). Deleuze (1986) también afirma que la voluntad de poder 
no es el ser ni tampoco el devenir. "La voluntad de poder se manifiesta como la sensibilidad de la fuerza; el elemento diferencial de las fuerzas se manifiesta como su sensibilidad diferencial" (p. 91). Es decir, es el poder de afectar y de ser afectado, lo cual remite a que ella se manifieste como la sensibilidad y la afectividad de toda fuerza. Desarrollemos esto a continuación.

\section{2 ¿QUÉ PUEDE UN CUERPO?}

TODO CUERPo es UNA COMPOSICión de relaciones de fuerzas desiguales que pueden ser interpretadas desde sus diferencias cualitativas (fuerzas activas y reactivas) y desde sus diferencias cuantitativas (cantidad de potencia). De este modo, se conforma un cuerpo intensivo y no substancial.

\subsubsection{Análisis de las relaciones diferenciales cualitativas}

Desde la perspectiva cualitativa de la diferencia de fuerzas, afirma Deleuze (1986):

Las fuerzas inferiores se definen como reactivas: no pierden nada de su fuerza, de su cantidad de fuerza, la ejercen asegurando los mecanismos y las finalidades, ocupándose de las condiciones de vida y de las funciones, las tareas de conservación, de adaptación y de utilidad. Este es el punto de partida del concepto de reacción (p. 61).

Las fuerzas reactivas se definen por su función o fin: conservar, adaptar, utilizar. Están siempre reguladas: siguen una regla, una ley, un límite, un impedimento. Lo reactivo se define desde el otro término de la relación, es decir, desde lo activo. Por eso las fuerzas reactivas parten siempre del límite, del impedimento, de lo que no se puede. Al respecto, Deleuze (1986) advierte:

Indudablemente caracterizar a estas fuerzas activas es más difícil. Ya que, por naturaleza, escapan a la conciencia: "La gran actividad principal es inconsciente"s. La conciencia expresa solamente la relación de algunas fuerzas reactivas con las fuerzas activas que las dominan. La conciencia es

5 Véase La voluntad de poder, II, 227 (Nietzsche, 2000, citado por Deleuze, 1986, p. 62). 
esencialmente reactiva ${ }^{6}$; por eso no sabemos lo que puede un cuerpo, de qué actividad es capaz (p. 62).

La conciencia ${ }^{7}$ es vista como un síntoma del cuerpo y no como su fundamento. Tomarla como síntoma es tomarla como efecto y no como causa. El síntoma no tiene que ser confundido con la causa. La conciencia es una mera superficie: aquella parte del cuerpo que se ve afectada por el mundo. Es un epifenómeno. Lo que le interesa remarcar a Deleuze es que la relación de la conciencia con lo exterior es siempre una relación entre dos fuerzas desiguales. Para Nietzsche la relación de fuerzas es lo que constituye el cuerpo. La conciencia siempre está en relación con lo no-consciente o con lo inconsciente. Ese inconsciente es el cuerpo. Lo inconsciente es activo, creativo, productivo, transformador (Etchegaray et al., 2011, p. 221). Por ello, afirma Deleuze (1986) que "[1]a conciencia: testimonia únicamente 'la formación de un cuerpo superior”' (p. 60) ${ }^{8}$. Este cuerpo superior es aquel en que prevalecen las relaciones de fuerzas activas. "¿Qué es lo que es activo? Tender al poder'. Apropiarse, apoderarse, subyugar, dominar son los rasgos de la fuerza activa. Apropiarse quiere decir imponer formas, crear formas explotando las circunstancias"10 (Deleuze, 1986, p. 63).

Las fuerzas activas sostienen siempre una tensión, una lucha, un antagonismo. Tienden a..., se dirigen a..., pero aquello a lo que se dirigen no es una substancia o un ser. Se dirigen al poder. Lo que quiere la fuerza es más poder. El poder no tiene que ser pensado como una cosa o un ser, ni como una propiedad de las cosas o de los sujetos, ni como una facultad, ni como el lugar que ocupan ciertos sujetos. "Tender al poder" es desarrollar ese poder, es desarrollar las fuerzas, es crear más fuerza. Lo que caracteriza a lo activo es la capacidad de crear, pero no

6 Véase La gaya ciencia, 354 (Nietzsche, 1990, citado por Deleuze, 1986, p. 62).

7 Recuérdese que la conciencia ha sido tomada como el fundamento desde Descartes. La existencia se fundamenta en el pensamiento, en la conciencia.

8 Véase La voluntad de poder, II, 227 (Nietzsche, 2000, citado por Deleuze, 1986, p. 62).

9 Véase La voluntad de poder, II, 43 (Nietzsche, 2000, citado por Deleuze, 1986, p. 62).

10 Véanse Más allá del bien y del mal, 259 (Nietzsche, 1972, citado por Deleuze, 1986, p. 63) y La voluntad de poder, II, 63 (Nietzsche, 2000, citado por Deleuze, 1986, p. 63). 
de crear cosas sino de crearse a sí mismo, de potenciarse y autoafirmarse. Sobre esto, afirma Deleuze (1986):

Cada vez que señalamos así la nobleza de la acción y su superioridad frente a la reacción, no debemos olvidar que la reacción designa un tipo de fuerzas del mismo modo que la acción: sencillamente, las reacciones no pueden captarse, ni comprenderse científicamente como fuerzas, si no las relacionamos con las fuerzas superiores que son precisamente de otro tipo. Reactivo es una cualidad original de la fuerza, pero que solo puede ser interpretada como tal en relación con lo activo, a partir de lo activo (p. 63).

Se trata de fuerzas en relación, no de relaciones entre cosas o propiedades de una substancia o un sujeto. Deleuze (1987, pp. 49 y ss.) tiene presente la teoría del poder de Foucault: el poder no es una propiedad, no es un lugar, no es una cosa, no es un atributo. No se tiene poder; se ejerce poder, se actúa. Toda fuerza es un ejercicio del poder. No existe una fuerza carente de poder. Una fuerza activa es aquella que hace todo lo que puede, lleva su fuerza al límite de lo que puede. Una fuerza reactiva nunca hace todo lo que puede, no lleva la fuerza al límite, sino que parte del límite. Foucault no habla de fuerzas reactivas sino de resistencias. No hay poder sin resistencia (Etchegaray et al., 2011, p. 231). Sin embargo, se trata siempre de una relación, el poder es relación. Aparece aquí una tesis central en la interpretación de Deleuze: no hay posibilidad de que se den dos fuerzas iguales. Es imposible eliminar las diferencias. Para Deleuze, este es el sueño de las fuerzas reactivas. Pero el problema aquí no es la igualación de las fuerzas, sino la reactivación de las fuerzas, que las fuerzas activas se conviertan en reactivas. Este problema es al que Nietzsche denominó nihilismo.

\subsubsection{Análisis de las relaciones diferenciales cuantitativas}

POR SU PARTE, LAS FUERZAS PUEDEN, también, ser interpretadas cuantitativamente, es decir, es posible saber qué cantidad de poder o potencia hay en cada una de ellas. Una fuerza existe en relación con otra fuerza difiriendo cuantitativamente en cuanto es más fuerte o más débil, es decir, tiene más poder o menos poder. 
[...] De hecho la potencia no existe más que como relación entre cantidades $[\ldots]$, la potencia $[. .$.$] es menos una cantidad que una relación entre cantida-$ des. [...] La potencia nunca es una cantidad absoluta, es una relación diferencial. Es una relación entre cantidades, de tal manera que la efectuación va siempre en un sentido o en el otro (Deleuze, 2008, p. 96).

Ahora bien, la cantidad de potencia que se expresa en las fuerzas está dada por la capacidad de afectar (crear relaciones) y ser afectado (por impresiones, pasiones, pensamientos, etc.). Pero la potencia que se expresa en las relaciones de fuerzas que conforman un cuerpo está efectuada totalmente a cada instante por las relaciones que lo conforman. Es decir, un cuerpo siempre efectúa: hace y padece, todo lo que puede, expresando un dinamismo intensivo en la constitución de todo cuerpo a través de la capacidad de afectar y ser afectado. Afirma Deleuze (2008) en sus clases sobre Spinoza que

[...] toda la potencia estaba en acto; que, literalmente, la potencia no estaba "en potencia", que toda potencia estaba en acto; que estrictamente había identidad de la potencia y del acto, es decir identidad de la potencia con lo que la cosa hace o padece. [...] Si es verdad que toda potencia está en acto, eso quiere decir que a cada instante está efectuada, jamás habrá un instante en que mi potencia tenga algo no efectuado (p. 96).

Podemos extraer, entonces, algunas consecuencias. En primer lugar, la cantidad de potencia que se expresa en las relaciones de fuerza que conforman todo cuerpo constituye la escala diferencial cuantitativa e intensiva que diferencia a unos entes de otros, en contraposición a la jerarquía trascendente de las esencias conforme al discurso de la tradición filosófica. En segundo lugar, las afecciones efectúan a cada instante la potencia tanto como pueden en función a las circunstancias del aquí y del ahora, es decir, de acuerdo con el conjunto de relaciones actuales, pues estas relaciones no existen independientemente de los afectos que la efectúan (Deleuze, 2008, p. 94). En tercer lugar, estamos en presencia de una comprensión dinámica y no estática de todo cuerpo, donde la potencia de un cuerpo puede aumentar o disminuir su cantidad de acuerdo con las relaciones de fuerza con las que entre en relación. Ello implica pensar la cantidad de potencia que hay en todo cuerpo como ondas oscilantes y no como sustancias autónomas. Por último, dijimos que la cantidad de potencia puede aumentar o disminuir. 
¿Cómo se produce el aumento o la disminución? Afirmamos arriba que la potencia está a cada instante totalmente efectuada por las afecciones. Y las afecciones efectúan la potencia de acuerdo con las relaciones de fuerzas que constituyen un cuerpo. Por ende, estas relaciones pueden ser depotenciadoras: en este caso la cantidad de potencia efectuada por las afecciones disminuye la potencia del cuerpo; pero también las relaciones de fuerza pueden incrementar el poder de la potencia del cuerpo: en este caso la cantidad de potencia efectuada por las afecciones aumenta.

En consecuencia, afirma Deleuze (2008) refiriéndose al cuerpo: “[...] [este] es una cantidad intensiva. Una cantidad intensiva no es para nada como una cantidad extensiva. Una cantidad intensiva es inseparable de un umbral, que es ya en sí misma una diferencia. La cantidad intensiva está hecha de diferencias" (pp. 239-240). En definitiva, la potencia es una relación diferencial intensiva entre cantidades que se apoderan del cuerpo y lo constituyen, por lo cual no puede ser definido con anterioridad o a priori de tales relaciones (Dosse, 2009, p. 191). De aquí la gran relevancia de la sentencia que Deleuze toma de Spinoza: no sabemos quépuede un cuerpo o de qué es capaz.

\section{Conclusiones}

EN TODO ACONTECIMIENTO SIEMPRE HAY UNA PLURALIDAD DE SENTIDO, una constelación de sentido. El sentido implica siempre relaciones plurales, una constelación. Una constelación es un sistema abierto en oposición a un sistema cerrado donde hay leyes que gobiernan el movimiento y las relaciones entre los elementos, aun cuando el sistema sea dinámico y variable. En una constelación eso no es posible, porque no se puede abarcar la totalidad y su conocimiento es siempre provisorio. La constelación incluye tanto las relaciones temporales como las espaciales. Así, la historia es la variación de esos sentidos en estas relaciones que se efectúan aconteciendo. En definitiva, todo acontecimiento tiene múltiples sentidos porque el acontecimiento es el sentido mismo que diferencia activamente. Con la noción de acontecimiento, Deleuze puede oponer otro carácter a la concepción cristiana y dialéctica de la historia, quienes la consideran sujeta a una legalidad necesaria y a una teleología que encamina los hechos hacia un fin único en el que se consuma todo el desarrollo. La noción de acontecimiento 
supone una relación contingente de las relaciones de fuerza en la historia. Si no, ¿cómo se produciría un acontecimiento como resultado de un movimiento dialéctico? Cuando se habla de acontecimiento hay que pensar en una multiplicidad de fuerzas. Los acontecimientos no se caracterizan por su duración sino por los efectos o múltiples sentidos que generan. Los acontecimientos no están precedidos por causas que permitan preverlos con anterioridad, sino que pueden resultar de situaciones mínimas, banales o imperceptibles ${ }^{11}$. De este modo, hay que pensar en una dinámica de las fuerzas ${ }^{12}$. En suma, a nivel de la efectuación, el acontecimiento se encarna en un estado de cosas que puede ser interpretado como flujo de fuerzas divergentes, que azarosamente forman constelaciones nuevas, que se actualizan en cuerpos de potencias diferentes y que mientan el sentido a través del lenguaje, conformando un plano de inmanencia.

La inmanencia es el campo de fuerzas generativas y productivas donde constantemente se actualizan multiplicidades, pero sin agotar su poder de cambio y sin impedir toda fundamentación o justificación última. El plano de inmanencia es un todo ilimitado que se presenta siempre abierto y que no totaliza sus partes en una unidad superior y absoluta, dado que este plano mienta un sistema de coordenadas, de diferentes dimensiones y orientaciones que producen constantemente conexiones que renuevan, a la vez, la totalidad del plano, ya que el estallido del acontecimiento y su efectuación conforma el plano de inmanencia. Este es un plano que se forja desde dos caras: una comprende al acontecimiento (en cuanto produce la individuación), la otra refiere al sentido (el concepto). El concepto deleuziano (a diferencia del concepto de la tradición metafísica) expresa las líneas de fuerzas y tensiones, los límites y las variaciones que constituyen al plano. Ello implica que no haya esencias trascendentes sino entrecruzamientos

11 Esta cuestión está muy bien presentada en la novela Crímenes imperceptibles, de Guillermo Martínez, 2003, volcada al cine con el título The Oxford Murders (2008), producida por Gerardo Herrero, Álvaro Agustín y Mariela Besuievsky, y dirigida por Álex de la Iglesia.

12 Aquí debemos tener en cuenta la teoría de las fuerzas que Deleuze desarrolla en su libro sobre Nietzsche y en sus clases sobre Spinoza, y que hemos trabajado de forma conjunta en Etchegaray, Esperón, et al., 2016. Deleuze sostiene que un cuerpo es una composición de relaciones de fuerzas desiguales que pueden ser interpretadas desde su diferencia cualitativa (fuerzas activas y reactivas) y desde su diferencia cuantitativa (cantidad de potencia); conformando, de este modo, un cuerpo intensivo y no substancial. 
(encuentros y desencuentros, conexiones y desconexiones) de fuerzas. El concepto es una singularidad que sintetiza intensidades diferenciales y no abstracciones. Él es una meseta estratificada de múltiples dimensiones, nunca cerrada y de conexiones virtualmente infinitas. En el concepto no hay totalizaciones universales o trascendentales sino conexiones o series conjuntivas ( Recordemos que para Deleuze pensar es crear ${ }^{13}$ - conectar conceptos- y este es el movimiento propio en donde se produce la actividad filosófica. El plano no preexiste a los conceptos, sino que a la vez que se crean los conceptos, las conexiones intensivas, así se constituye el plano como receptáculo conceptual que es el medio para toda creación y conexión posible. En definitiva, el pensamiento se ex-pone en el plano a la vez que se experimenta creando conceptos. Esto significa que hay simultáneamente e interrelacionados pensamiento (sentido) y acontecimiento (realidad) y que, además, por un lado, se distribuye (el plano) como realidad y, por otro, se interpreta como sentido. Es decir, el sentido es inseparable del acontecimiento y el acontecimiento mismo es inseparable del devenir de la vida, cuyo carácter radical es siempre retornar ${ }^{14}$.

Sostener la constitución inmanente del acontecimiento implica rechazar los fundamentos absolutos y las verdades universales. El peligro que ha acechado y acecha a todo sistema inmanente es atribuirlo a alguna cosa, v. g., al espíritu, a la substancia, a la idea, etc. Ello implica la constitución de universales abstractos o trascendentales que son propios de la tradición filosófica y del modo de fundamentación onto-teo-lógico. La realidad inmanente del acontecimiento refiere a la potencia con la que el ser se alza contra la nada, instituyendo al devenir mismo como la actividad inmanente del acontecimiento. Mengue (2008) define la inmanencia como "el encuentro de múltiples dimensiones o líneas de fuerza que se entrecruzan sin que una se eleve para cumplir el rol de unidad trascendente. La inmanencia reconduce al pluralismo" (p. 72). De este modo, la realidad aparece

13 Crear en la filosofía deleuziana sugiere trazar líneas de fuga que fisuren y atraviesen los sistemas estables.

14 El sentido de la noción de vida en Deleuze no debe confundirse con una noción orgánica ni evolucionista de esta, sino que debe ser comprendido como puro devenir, sin forma, a-significante, no orgánica ni organizada, como apertura que potencia la transgresión de todo límite, como fuerza expansiva que desborda todo orden político o jerárquico. 
sobre un plano inmanente de múltiples dimensiones, constituidas, ellas, de diferentes líneas o relaciones de fuerza: líneas de despliegue o transformación (líneas de fuga); o líneas de reposo o estabilización (estratos o segmentos) ${ }^{15}$.

En suma, el acontecimiento es devenir inmanente, flujo de tiempo que siempre retorna, ya que retornar es el ser del mismo devenir, el ser que se afirma en el devenir. Deleuze comprende al retorno como repetición, pero no como repetición de lo mismo, de lo idéntico, sino que la repetición es de lo que difiere, es decir, de la diferencia, ${ }^{16}$ esto es, repetición de la posibilidad del acontecimiento cuyas relaciones, conexiones de fuerzas y efectuaciones corporales son siempre novedosas y originales. No es el ser el que retorna, el que vuelve, sino que es el propio retornar: el acontecimiento en cuanto se afirma en el devenir, y ello sucede eternamente. El eterno retorno es la potencia del ser del devenir que acontece en su absoluta y radical contingencia.

En definitiva, lo que retorna es siempre lo que difiere. No hay sujeto o substrato que subyazca al volver. Tampoco es la diferencia quien regresa como un soporte del movimiento conservándose a sí misma, porque la diferencia no deja

15 De este modo, la genealogía se convierte en una cartografía o diagrama: estudio de las líneas, sus caminos, sus movimientos sobre el plano. Recordemos que Deleuze señala tres clases de líneas: 1) las primeras son rígidas, son líneas duras 'molares', muestran un devenir sedentario, cortan y recortan la actividad, el movimiento. Segmentarizan y estratifican el devenir en forma rígida y según oposiciones duales (unidad/multiplicidad, hombre/mujer, esencia/apariencia, etc.), y mientan un plano de organización (orden social y político, esto refiere al aparato del Estado en cuanto máquina sobrecodificada y abstracta). 2) Hay otras líneas más flexibles, son líneas migrantes 'moleculares'. Muestran umbrales móviles y cambiantes, operan microdevenires y ponen en juego intensidades que fluyen entre los segmentos, socavándolos. Estas líneas reterritorializan. 3) Por último, Deleuze señala las líneas de fuga, son líneas nómadas, son creadoras de desterritorializaciones. Ellas escapan a todo dualismo rígido e inventan conexiones nuevas, imprevistas e imprevisibles. Estas líneas componen lo que Deleuze llama 'máquina de guerra' que no tiene que ver con la guerra sino con la marca negativa que deja en la 'historia oficial'. La máquina de guerra es un agenciamiento lineal de fuga, compone un espacio 'liso' que se propaga al modo de un virus, mienta un devenir revolucionario (agenciamientos colectivos e inventivos). Solo cuando se las separa de lo que ellas pueden cambian de sentido y de regímenes de signos (v. g. de guerrilla a operación militar) y se las apropia el estado (máquina abstracta que sobrecodifica el plano).

16 El eterno retorno es el 'para sí' de la diferencia, en cuanto eterno retorno de lo diferente, es decir, lo que se repite es la posibilidad de las diferencias. Pero el 'en sí' de la diferencia es lo que Deleuze (2002) nombra en Diferencia y repetición como 'precursor sombrío', que pone en relación las series heterogéneas. 
de afirmarse, reproducirse y repetirse como siendo siempre otra, por lo cual no hay mismidad ni identidad o fundamento estable en donde pueda apoyarse. Por ello, volver es el ser de la diferencia y del acontecimiento. Pero téngase en cuenta que las diferencias que se han actualizado, i. e., la extensión, el pensamiento, los entes (cuerpos o modos de ser) no pueden volver; lo que vuelve y se repite es la condición de posibilidad de todo ente en su dimensión intensiva, y esto es a lo que llamamos el acontecimiento; por eso, la diferencia es diferenciante, es decir, produce las diferencias activamente. Así, el eterno retorno es y se dice de la diferencia en cuanto a su intensidad, lo que hace que el retorno no sea de lo mismo o de lo igual, sino siempre de lo diferente. De aquí se infiere el sentido unívoco que Deleuze le confiere al ser. "Las diferencias vuelven, el ser es el volver de las diferencias, sin que haya diferencias en su manera de volver y decir el ser" (Mengue, 2008, p. 266). Esto significa que no es el ser el que vuelve y subyace a las diferencias que distribuye, el substrato del volver no es el ser; son las diferencias y de estas el hecho de que retornan de lo que se dice que son, de las que se dicen que 'vuelven', en un solo y mismo sentido.

Tenemos que hacer referencia aquí a una de las tesis centrales de la filosofía de Deleuze, a saber, la univocidad del ser. Debemos analizar cómo debe comprenderse tal tesis, ya que puede dar lugar a muchos equívocos. En Lógica del sentido Deleuze (1989) afirma que "la univocidad del ser significa que el ser es Voz, que se dice, y se dice en un solo y mismo sentido de todo aquello de lo que se dice. Aquello de lo que se dice no es en absoluto lo mismo. Pero él es lo mismo para todo aquello de lo que se dice" (p. 186). Lo anterior se debe a que la univocidad se refiere a que el ser es lo mismo (diferencia) para todos los entes de los que se dice. $Y$ esta diferencia se dice en un solo y mismo sentido como eterno retorno de la diferencia. Esto implica la infinita posibilidad de la emergencia de la singularidad, el azar como regulador necesario para el estallido y la irrupción del acontecimiento como instancia única en la que se juega la apertura de la realidad. Todo lo anterior ocurre en un solo y mismo sentido.

La univocidad del ser significa que es lo mismo, lo que se repite y diferencia eternamente: la posibilidad diferencial de que haya acontecimiento, efectuación y sentido. La univocidad del ser, afirma Deleuze (1989), pone en contacto y relaciona tanto al sentido como al acontecimiento, ya que es "un solo y mismo ser para lo imposible, lo posible y lo real” (p. 187). En suma, para Deleuze la 
repetición del acontecimiento como diferencia inmanente es la ontología que le permite sostener la univocidad del ser. Así, estos elementos se convierten en los ejes centrales de una nueva ontología y, a su vez, en elementos para una crítica radical del pensamiento representativo, de la identidad y del fundamento. Por ello Deleuze (2002) afirma: "una sola y misma voz para todo lo múltiple de mil vías, un solo y mismo océano para todas las gotas, un solo clamor de ser para todos los entes" (p. 389).

\section{Referencias}

Deleuze, G. (1986). Nietzsche y la filosofía. Barcelona: Anagrama.

Deleuze, G. (1987). Foucault. Buenos Aires: Paidós.

Deleuze, G. (1989). Lógica del sentido. Barcelona: Paidós.

Deleuze, G. (2002). Diferencia y Repetición. Buenos Aires: Amorrortu.

Deleuze, G. (2008). En medio de Spinoza. Buenos Aires: Cactus.

Deleuze, G., \& Guattari, F. (2003). Rizoma. Valencia: Pre-Textos.

Dosse, F. (2009). Gilles Deleuze y Félix Guattari. Biografía cruzada. Buenos Aires: Fondo de Cultura Económica.

Etchegaray, R., et al. (2011). La rebelión de los cuerpos. Buenos Aires: Editorial Unlam.

Etchegaray, R., Esperón, J. P., et al. (2016). Acontecimiento y creatividad en la filosofia de Gilles Deleuze. Un nuevo modo de sentir y percibir. Buenos Aires: Editorial Unlam-Prometeo.

Martínez, G. (2003). Crímenes imperceptibles. Buenos Aires: Planeta.

Herrero, G., Agustín, A. \& Besuievsky, M. (Productores), \& De la Iglesia, Á. (Director). (2008). The Oxford Murders [Largometraje]. Reino Unido, Francia, España: Odeon Sky Filmworks \& Magnolia Pictures.

Mengue, P. (2008). Deleuze o el sistema de lo múltiple. Buenos Aires: Las Cuarenta.

Nietzsche, F. (2000). La voluntad de poder. Madrid: Editorial EDAF.

Nietzsche, F. (1991). La gaya ciencia. Caracas: Monte Ávila Editores.

Nietzsche, F. (1972). Más allá del bien y del mal. Madrid: Alianza Editorial. 
Scannone, J. C. (2010). Introducción general: El 'nuevo pensamiento' y el 'otro comienzo'. En: J. C. Scannone. (Ed.). Un nuevo pensamiento para otro mundo posible. Córdoba: EDUCC.

Spinoza, B. (2000). Ética. Madrid: Trotta.

Schérer, R. (2012). Miradas sobre Deleuze. Buenos Aires: Cactus.

Jaquet, C. (2007). Deleuze y su lectura conjunta de Spinoza y Nietzsche. Instantes y Azares-Escrituras Nietzscheanas, VII(4-5)

Žižek, S. (2014). Acontecimiento. Madrid: Editorial Sexto Piso. 